\title{
Characterization and Fabrication of Metakaolin using Pulau Bangka Kaolin
}

\author{
Sotya Astutiningsih ${ }^{1}$, Irwin M. Banjarnahor ${ }^{1}$ and Ahmad Zakiyuddin ${ }^{1 *}$ \\ ${ }^{1}$ Department of Metallurgical and Materials Engineering, Faculty of Engineering, Universitas Indonesia, Depok 16424, Indonesia
}

\begin{abstract}
Geopolymer material is an advanced material that is now being looked for its use as a refractory material, additive for building material, as well as other applications. Geopolymer is produced by polymerizing the precursor used in the process. One of the common precursors being used as geopolymer is metakaolin. The metakaolin was produced by thermal treatment (calcination) of kaolin minerals, which will convert its mineral structure from crystaline into amorphous and make it more reactive. This paper presents the fabrication and characterization of metakaolin using kaolin from Bangka island. The main structure of kaolin used in this study are kaolinite and muscovite according to XRD results obtained. Metakaolin was produced by thermal treatment using three different calcination temperatures ranged from 600 to $700^{\circ} \mathrm{C}$ and calcined for 4 hours. Prior to calcination, some specimens will be mechanically milled using planetary ball mill for 15 minutes with the milling speed of $20.00 \mathrm{rad} / \mathrm{s}$ and will also be calcined with the same parameter. As a comparison, commercial metakaolin MetaStar also be used to compare it to all metakaolin produced. All metakaolin produced are characterized by XRD and SEM, and STA test will be performed to kaolin to examine its thermal behavior. The STA test performed to both milled and non-milled sample shows that dehydroxylation and reconstruction process occurs at temperature range of $460-520^{\circ} \mathrm{C}$ and $520-640^{\circ} \mathrm{C}$ for kaolin sample, and at temperature of $426-537^{\circ} \mathrm{C}$ and $537-618^{\circ} \mathrm{C}$ for milled kaolin sample. XRD pattern obtained shows that almost all metakaolin produced have the relatively similar pattern to each other as well as to MetaStar, with the main peak of quartz $\left(\mathrm{SiO}_{2}\right)$ at 2 疽 $=26.60^{\circ}$ to $26.65^{\circ}$. The SEM results shows the characteristic layered-laminate plate-like structure of kaolin. Compared to another SEM results obtained, it can be concluded that there are no changes to the visible structure of metakaolin produced with the same kaolin used after calcination.
\end{abstract}

\section{Introduction}

In the present day, there is an interest of utilizing kaolin in construction industry, mainly as a supplementary cementitious materials (SCM). SCMs are materials used to replace some part of the clinker in a cement or cement in a concrete mixture. The SCMs from kaolin is produced by thermal treatment to make it more reactive, i.e, calcination within a definite temperature range. The results of this calcination are known as metakaolin.

In Indonesia, there is an abundant deposit of kaolin in Bangka Island, which mainly used for paper filler in paper industry, or as a mixture in paint industry. To increase the value of the mineral, it can be used as the SCMs explained before by calcined the kaolin to obtain product known as metakaolin.

Kaolinite is the main structure of kaolin mineral. Kaolinite consist of aluminosilicate hidrate compound $\mathrm{Al}_{2} \mathrm{Si}_{2} \mathrm{O}_{5}(\mathrm{OH})_{4}$ which consist of Si-O crystal tetrahedral layer $\left(\mathrm{SiO}_{4}\right)$ connected with alumina crystal octahedral layer $(\mathrm{Al}(\mathrm{O}, \mathrm{OH}) 6)^{[1]}$. During calcination, the main reaction which occured is the breaking off the kaolinite structure. The heating reaction breaks off $-\mathrm{OH}$ chain from the mineral, and collapsing the kaolinite structure, resulting in an amorphous aluminosilicate structure $\left(\mathrm{Al}_{2} \mathrm{O}_{3} \cdot 2 \mathrm{SiO}_{2}\right)$ known as metakaolinite. Theoritically, there are three stages of thermal transformation of kaolinite to metakaolinite[2-5]:

- When the heating process begin, kaolinite structure will break down and separate the alumina layer and silicate layer and break down the long order structure. This process occured until the heating temperature reach $400^{\circ} \mathrm{C}$, caused by the dehydroxilation of hydroxil structure in the layer which cause the water crystal to evaporate and leave the main structure.

- Kaolinite structure in kaolin mineral will break by the releasing of water crystal compound which happened in relatively low temperature $\left(100-200^{\circ} \mathrm{C}\right)$ and continuously occurred until the temperature reach $400^{\circ} \mathrm{C}$. This stage happened with the first stage simultaneously. In dehydroxylation process, $-\mathrm{OH}$ group will be separated to form $\mathrm{H}^{+}$and $\mathrm{O}^{2-}$ ion. The proton will link to another -OH group to form water molecules which will be evaporated during the

*corresponding author. E-mail:zakiyuddin@metal.ui.ac.id, Tel. +62-21-7872350. 
process. The $\mathrm{O}^{2-}$ ion will stay in the crystal lattice of metakaolinite which will be formed after the next reconstruction stage occurred.

- After a while, the broken kaolinite layer structure will experience reconstruction process. At temperature about $600^{\circ} \mathrm{C}$, alumina and silica layer structure reconstruction will undergo to form metakaolinite $\left(\mathrm{Al}_{2} \mathrm{Si}_{2} \mathrm{O}_{7}\right)$ with crystal structure and orientation are similar to kaolinite.

The dehydroxilation reaction from the explanation above can be expressed as follows[6]:

$$
\mathrm{Al}_{2} \mathrm{Si}_{2} \mathrm{O}_{5}(\mathrm{OH})_{4} \rightarrow \mathrm{Al}_{2} \mathrm{Si}_{2} \mathrm{O}_{7}+2 \mathrm{H}_{2} \mathrm{O}
$$

If the calcination is done at higher temperature (925$950^{\circ} \mathrm{C}$ ), the formed metakaolin structure will become aluminium-silicon spinel structure $\left(\mathrm{Si}_{3} \mathrm{Al}_{4} \mathrm{O}_{12}\right)$, expressed as follows:

$$
2 \mathrm{Al}_{2} \mathrm{Si}_{2} \mathrm{O}_{7} \rightarrow \mathrm{Si}_{3} \mathrm{Al}_{4} \mathrm{O}_{12}+\mathrm{SiO}_{2}
$$

Calcination done in even higher temperature $\left(\sim 1050^{\circ} \mathrm{C}\right)$ will cause the spinel structure changed to mullite structure $\left(3 \mathrm{Al}_{2} \mathrm{O}_{3} \cdot 2 \mathrm{SiO}_{2}\right)$ and further heating (at $1200^{\circ} \mathrm{C}$ ) will change amorphous $\mathrm{SiO}_{2}$ structure to become cristobalite $\mathrm{SiO}_{2}$, expressed as follows:

$$
\begin{gathered}
3 \mathrm{Si}_{3} \mathrm{Al}_{4} \mathrm{O}_{12} \rightarrow 2 \mathrm{Si}_{2} \mathrm{Al}_{6} \mathrm{O}_{13}+5 \mathrm{SiO}_{2 \text { (amorf) }} \\
\mathrm{SiO}_{2 \text { (amorf) }} \rightarrow \mathrm{SiO}_{2 \text { (cristobalite) }}
\end{gathered}
$$

The properties of metakaolin resulted from calcination process depends on the time of calcination and the temperature used to calcine the kaolin. The ideal temperature used according to some previous research is at $550-800^{\circ} \mathrm{C}[7]$. However, the calcination time used in several research is different depends on the source of kaolin used in the study[7]. The different sources result in different structure and mineral contained in the kaolin, hence become the reason of selecting the best calcination variable to produce high quality metakaolin.

Mechanical treatment by milling is one method used to increase the reactivity of metakaolin produced in the calcination process. There are already significant number of research done in the past which studying the effect of the treatment to the properties of metakaolin produced. The mechanical treatment was found to reduce particle size and increase the specific surface area of the particle. When milled, the structure will experience the gradual structural disordering, which result in the amorphization of kaolinite. The amorphous structure will result in the more pozzolanic metakaolin, which already been studied [8][9].

Pozzolanic is properties which describes the ability of material to perform a reaction to calcium (lime) with the existence of water in the reaction environment to form a cementitious properties substance[10]. To measure or know the properties in a material, there is two methods exist to measure it; direct and indirect method. Direct method based on the using of instrument to characterize the material properties with or without need to know the pozzolanic reaction happen to metakaolin. Whereas the indirect method based on the modification of mechanical properties from the cement with the addition of metakaolin.

The goal of this study is to determine the optimal calcination for obtaining metakaolin with the mostsimilar properties with many commercial metakaolin produced. In this study, MetaStar, a commercial metakaolin, was used as a comparison. Moreover, the mechanical treatment given in the process is studied to study its effect to the properties of metakaolin produced. This study used direct method determination, where in this case the pozzolanic of metakaolin produced was determined without the involvement of pozzolanic reaction.

\section{Materials and method}

\subsection{Properties of Kaolin clay}

Kaolin samples are obtained from Bangka Island.The major material constituent is kaolinite $\mathrm{Al}_{2} \mathrm{Si}_{2} \mathrm{O}_{5}(\mathrm{OH})_{4}$ $88.20 \%$ and muscovite $\mathrm{KAl}_{2}(\mathrm{SI}, \mathrm{Al})_{4} \mathrm{O}_{10}(\mathrm{OH})_{2} \quad 12.80 \%$ based on XRD characterization result. The XRD characterization was done with profile fitting procedure in $20-45^{\circ}$ 2国 range. The commercial metakaolin with product name MetaStar used in this study were obtained from Imerys Group@ $($. This commercial metakaolin is used as a comparison to the metakaolin produced using Bangka Island kaolin.

\subsection{Milling Procedure}

Kaolin clay was mechanically treated using ball mill. A cylindrical steel filled with steel balls used as a milling media. The angular velocity of the milling machine was about $20 \mathrm{rad} / \mathrm{min}$. In 15 minutes, about 50-60gr kaolin in each cylinder was milled in each milling run.

\subsection{Calcination Procedure}

Calcination is done using a muffle furnace with maximum temperature of $1200^{\circ} \mathrm{C} .200 \mathrm{gr}$ of kaolin and/or 150 gr of treated kaolin was calcined in 4 hours using borosilicate heat resistant glass as a calcination media. Both of the kaolins are calcined at temperature of 600 , 650 , and $700^{\circ} \mathrm{C}$. The sample will be named as follows:

Table 1. Samples codename of each variable

\begin{tabular}{|c|c|c|}
\hline Temperature & Non-milled & Milled \\
\hline $600^{\circ} \mathrm{C}$ & MK600 & MK600-MT \\
\hline $650^{\circ} \mathrm{C}$ & MK650 & MK650-MT \\
\hline $700^{\circ} \mathrm{C}$ & MK700 & MK700-MT \\
\hline
\end{tabular}

\subsection{Characterization}

\subsubsection{Particle size distribution (PSD)}


Particle size distribution is used to know the size distribution of the kaolin particle either milled or nonmilled. The particle size distribution was measured by Particle Size Analyzer (PT Indocement, Tbk.). The results of the characterization are shown in Fig. 2.

\subsubsection{Simutaneous Thermal Analysis [STA]}

Thermal behavior of both kaolin was investigated from the room temperature up to $950^{\circ} \mathrm{C}$ using a DSC-TGA instrument (CMPFA FTUI), with a heating rate of $20^{\circ} \mathrm{C} / \mathrm{min}$.

\subsection{3. $X$-Ray Diffraction (XRD)}

The XRD data were collected using X-Ray Diffraction Machine (Balai Penelitian Pascapanen) in the 2娄 range 20-45 (step-length: 0.02, time per step: 76.8).

\subsubsection{Scanning Electron Microscopy (SEM)}

SEM characterization is used to examined the morphology of each metakaolin produced by calcination in each calcination parameter, using INSPECT F50 SEM machine (CMPFA FTUI).

\section{Results and discussion}

\subsection{Simultaneous Thermal Analysis and Particle Size Distribution}

The raw kaolin and the milled kaolin used in this study were analyzed by Thermogravimetric Analysis (TGA) and Dfferential Scaning Calorimetry (DSC) simultaneously to examine the thermal reaction during the calcination process from $50^{\circ} \mathrm{C}$ up to $950^{\circ} \mathrm{C}$ at the rate of $20^{\circ} \mathrm{C} / \mathrm{min}$. The results are showed in Fig. 1 and Fig. 2 .

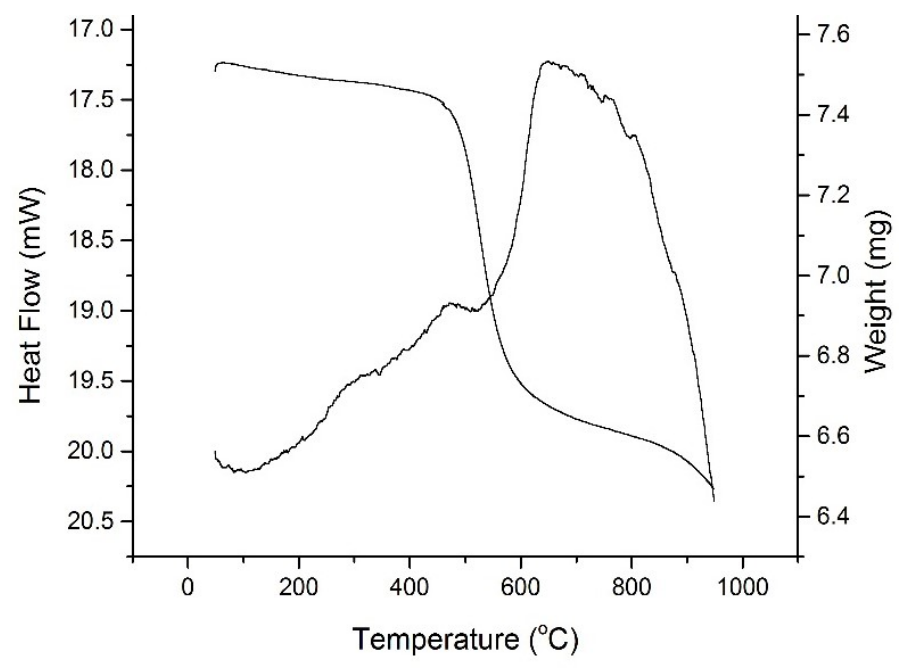

Fig. 1. STA graphic of Kaolin

At the low temperature between $50^{\circ} \mathrm{C}$ and $100^{\circ} \mathrm{C}$, the endothermic reaction occurs as in this condition the kaolin was absorbing heat and releasing the water absorbed onto the surface. At temperature of $100^{\circ} \mathrm{C}$ to $460^{\circ} \mathrm{C}$, kaolin started to lose its mass with a relatively low rate, which was caused by the dehydration process whichleads to dehydroxilation and reconstruction process at higher temperature. Dehydroxilation of kaolinite structure occurs at temperature between $460^{\circ} \mathrm{C}$ and $520^{\circ} \mathrm{C}$ when the materials experiencing endothermic reaction by absorbing heat to release $-\mathrm{OH}$ from the main structure and form water molecule which will be evaporated through the process. At the same condition, the TGA graph shows a significant loss of mass which illustrates the previous process occured. The reconstruction process occurs when exothermic reaction takes place at temperature range of $520^{\circ} \mathrm{C}$ to $640^{\circ} \mathrm{C}$. At this condition the heat released because of the newly reconstructed structure, and at the same time the mass loss still occuring as can be seen from the graph. At a higher temperature, the metakaolin formed as the reconstructed structure as explained earlier. The STA test to kaolin have been done in several previous research and shows the relatively similar results as above [11].

In this study, mechanical treated kaolin was also calcined. Fig. 2 below is the result of characterization of milled kaolin sample.

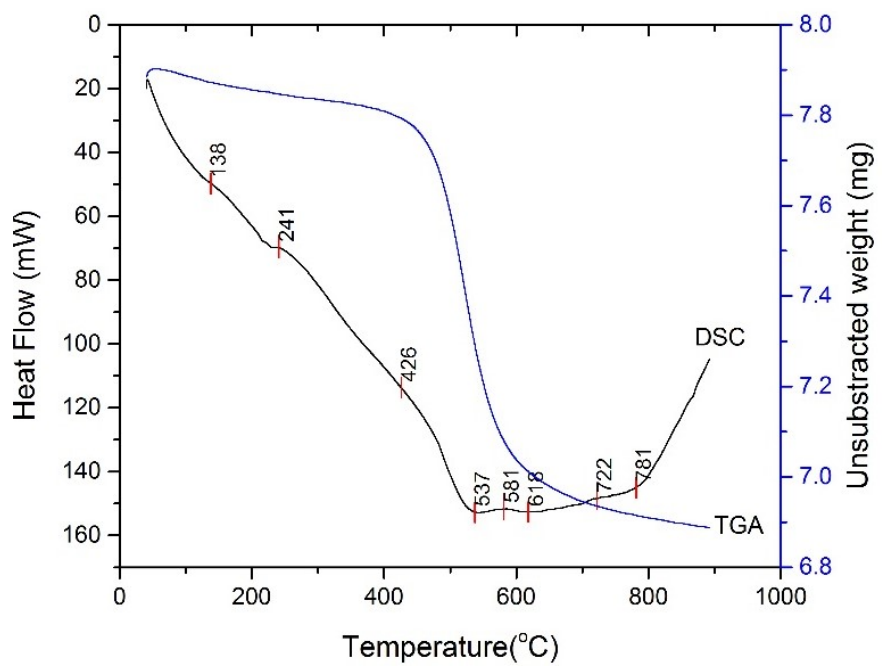

Fig 2. Particle size distribution graphic of kaolin, milled kaolin and MetaStar

From the result above, it clearly seen that the graphic showed have significant difference from the previous result (fig. 1). The temperature which describes the three stages of metakaolin forming was also changed as can be seen above. The reaction tends to be endothermic, as the DSC graphic showed is continuously going down until the temperature of $537^{\circ} \mathrm{C}$. The endothermic reaction occurs because the absorbed heat from the environment by the milled kaolin sample is used to release water and light impurities. The dehydroxilation of the structure occurs at temperature between $426^{\circ} \mathrm{C}$ and $537^{\circ} \mathrm{C}$, as in the DSC graphic the line seems to keep going down which indicates endothermic reaction occurs, and also in TGA graphic which showed the significant mass loss which indicates the release of - $\mathrm{OH}$ groups from the kaolin structure. The reconstruction process occurs when exothermic reaction takes place at temperature between $537^{\circ} \mathrm{C}$ to $618^{\circ} \mathrm{C}$. At this condition the exothermic reaction occurs which can be seen from the showed 
graphic that starts to going up at the temperature $537^{\circ} \mathrm{C}$. The exothermic reaction is occurred because ot the heat released from the newly reconstructed structure which known as the metakaolin.

The effect of mechanical treatment to thermal behavior had been studied before $[9,12]$. As we can see roughly from the graphic, the thermal behavior graphic result tends to be shifted to the left, because of the early dehydroxilation and reconstruction process occurred in the milled kaolin sample compared to the raw kaolin sample. In the detailed temperature, the dehydroxylation and reconstruction process from the raw kaolin sample occurred at temperature $460-520^{\circ} \mathrm{C}$ and $520-640^{\circ} \mathrm{C}$ for kaolin sample, and at temperature $426-537^{\circ} \mathrm{C}$ and $537-$ $618^{\circ} \mathrm{C}$ for milled sample. It can be occurred because of the mechanical treatment will increase the specific surface area and surface activation of kaolin particle which will lead to early dehydroxylation and reconstruction [13].

The particle size was also determined using Particle Size Distribution and presented in Fig.3.

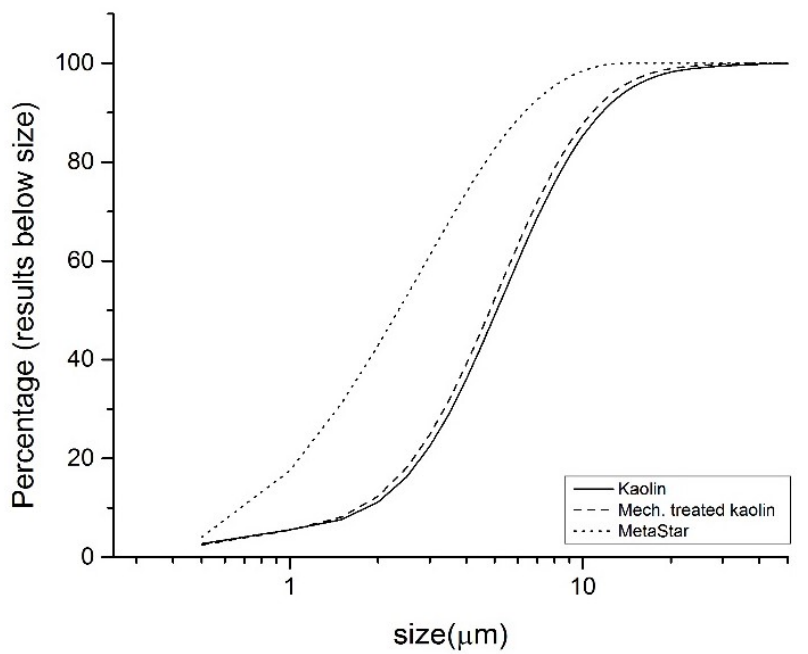

Fig.3. Particle size distribution graphic of kaolin, milled kaolin and MetaStar

The size distribution was determined by counting on how many particles are exceed to some size variable given in the calculation. In this case, the more left the line located, the finer the particle size will be. It can be explained as the finer particle will reach the 100 percentage earlier than the coarser one. In fig. 3, it can be seen that the MetaStar line is located in the far left than both the milled and not milled kaolin, which indicates that MetaStar have the finest particle size compared to other. The kaolin and milled kaolin size distribution were not significantly different as both line closed to each other with the milled kaolin located in the left. It indicates that the milling treatment done in this research cannot reduce the particle size further.

\subsection{XRD Pattern}

In order to see the changes which may occur during calcination, the XRD patterns of kaolin and metakaolin obtained were compared. The results are presented in fig. 4.
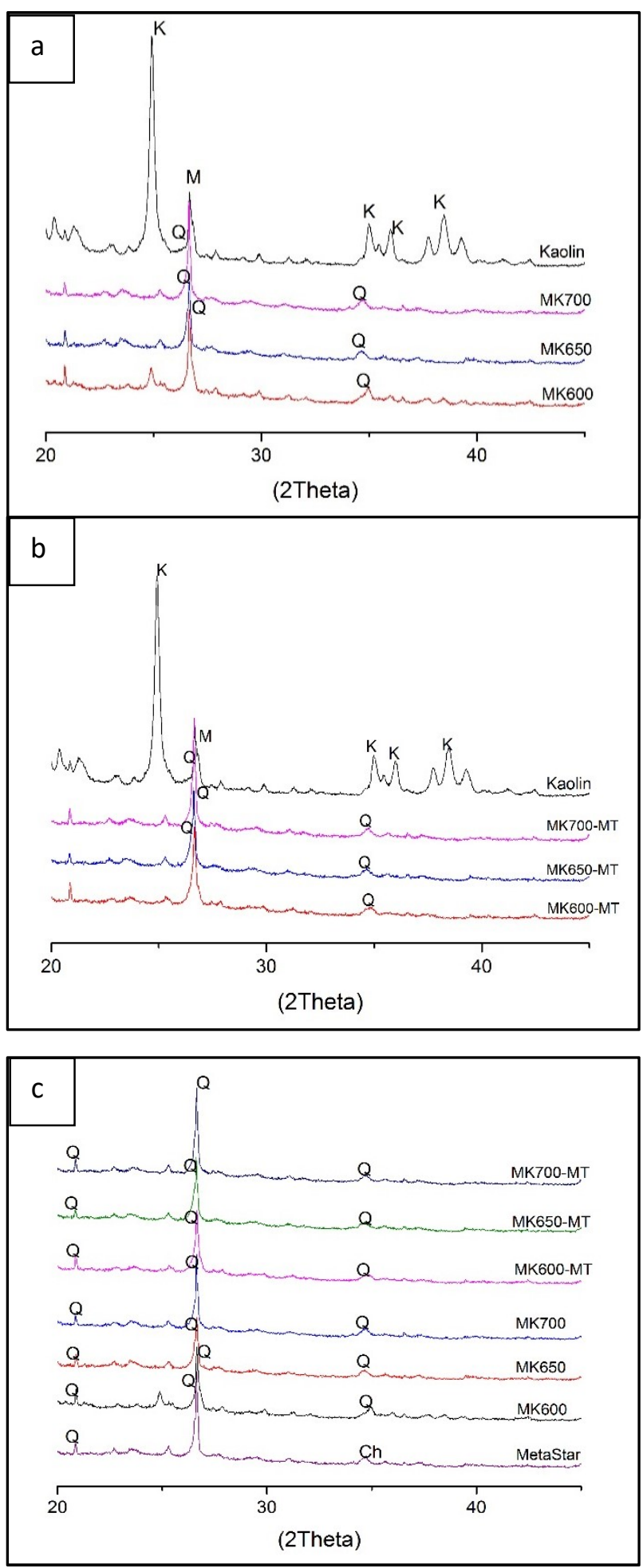

Fig. 4. Comparison of XRD pattern graphic of: a) Kaolin vs MK-MT, b) Kaolin vs MK, c) MetaStar vs all metakaolin (K= Kaolinite, $\mathrm{M}=$ Muscovite, $\mathrm{Q}=$ Quartz, $\mathrm{Ch}=$ Chromphyllite)

Fig.4a shows the diffraction pattern of kaolin compared to five metakaolin produced without mechanical treatment at each temperature. It can be seen that during calcination at temperature of 600,650 , and $700^{\circ} \mathrm{C}$, the main peak from kaolin (kaolinite: 2国= $24.92^{\circ}$ ) dissapear. On the other hand, the muscovite peak at 2 偪 $=26.80^{\circ}$ still exist, but changes and become the main peak of each metakaolin and turns to be quartz $\left(\mathrm{SiO}_{2}\right.$ at 2 望 $=26.60^{\circ}$ to $\left.26.65^{\circ}\right)$ during the calcination of 
each temperature. The other non-primary kaolinite peak at 2 望 $=35.92^{\circ}, 38.51^{\circ}$ have the same experience which dissapear when the kaolin calcined and turns to be quartz with low intensity. Characterization of metakaolin has been studied previously by several researcher and results in a similar diffraction pattern and tendency $[12,14]$.

In fig. $4 \mathrm{~b}$, the same results are shown as the previous graphic. Metakaolin produced at temperature of 600 to $700^{\circ} \mathrm{C}$ have the similar diffraction pattern to each other, with quartz as a main peak at2望 $=26.60^{\circ}$ to $26.65^{\circ}$ range.

Compared to commercial metakaolin MetaStar, it seems that all metakaolin produced almost have thesame pattern to each other (with the exception of MK800MT). At fig. 4c, it can be seen that the main peak of MetaStar (quartz, 2凅 $=26.65^{\circ}$ ) is located almost in the same angle as the other metakaolin. It can be seen that all quartz peak stacked in the same diffraction angle. Although, there was a slight difference in the nonprimary peak, at 2盗 $=34.75^{\circ}$ the MetaStar diffraction pattern have chromphyllite peak. At the other hand, the rest of metakaolin have quartz peak at the same diffraction angle.

Because of the temperature used which is not exceed the forming temperature $\left(640^{\circ} \mathrm{C}\right)$ from STA graph above (fig. 1), it does not mean that MK600 and MK600-MT produced did not classified as metakaolin. By seeing the diffraction pattern in fig. $3 \mathrm{c}$, that is confirmed that both of metakaolin produced at temperature of $600^{\circ} \mathrm{C}$ are indeed metakaolin. The thermal behavior results obtained from STA test are not time-dependent, as in this study the calcination process occurs in 4 hours, which is the reason why metakaolin already formed even at $600^{\circ} \mathrm{C}$ temperature.

\subsection{Scanning Electron Microscope}

SEM characterization was done to observe and analyze the morphology of kaolin, metakaolin, and MetaStar particle and compare them to each other. There are 5 samples which will be characterized: kaolin, milled kaolin, MetaStar, MK700 and MK700-MT. Both of the $700^{\circ} \mathrm{C}$-calcined metakaolin were chosen as a representative among the 6 metakaolin produced in this study.
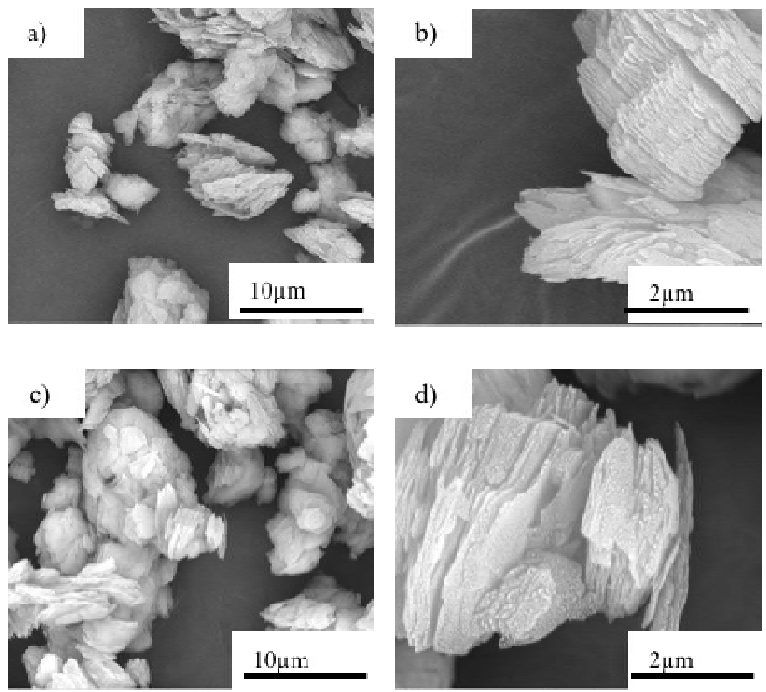

Fig.5. SEM morphology of: a) kaolin 10000x, b) kaolin 50000x, c) milled kaolin 10000x, d) milled kaolin 50000x magnification

The morphology of all materials characterized is presented in fig.5 and fig.6. The particle of raw kaolin (fig.5a) tends to be globular shaped and have a plate-like hexagonal layered structure which is the main characteristic of kaolin structure (fig. 5b). As the raw kaolin milled, the round-edged particles of raw kaolin changes to a rigged-edge particle and experience the slightly decrease in particle size (fig. $5 \mathrm{c}$ and $5 \mathrm{~d}$ ). The plate-layered structure still exists in the milled kaolin, which can be concluded that the mechanical treatment alone cannot break the primary structure.

The MK700 and MK700-MT particle morphology however, have almost the same morphology as each starting kaolin used. MK700 which used raw kaolin as a starting kaolin have the same globular-shaped particle which still have the laminated-layered plate structure which can be seen in fig.6d. On the other hand, the mechanically treated metakaolin particle has a roughedged shape seen at 50000x magnification, different from the MK700 (fig. 6f). This occurred because of the mechanical treatment given which breaks the globularshaped/round-edged particle and results to this morphology. 

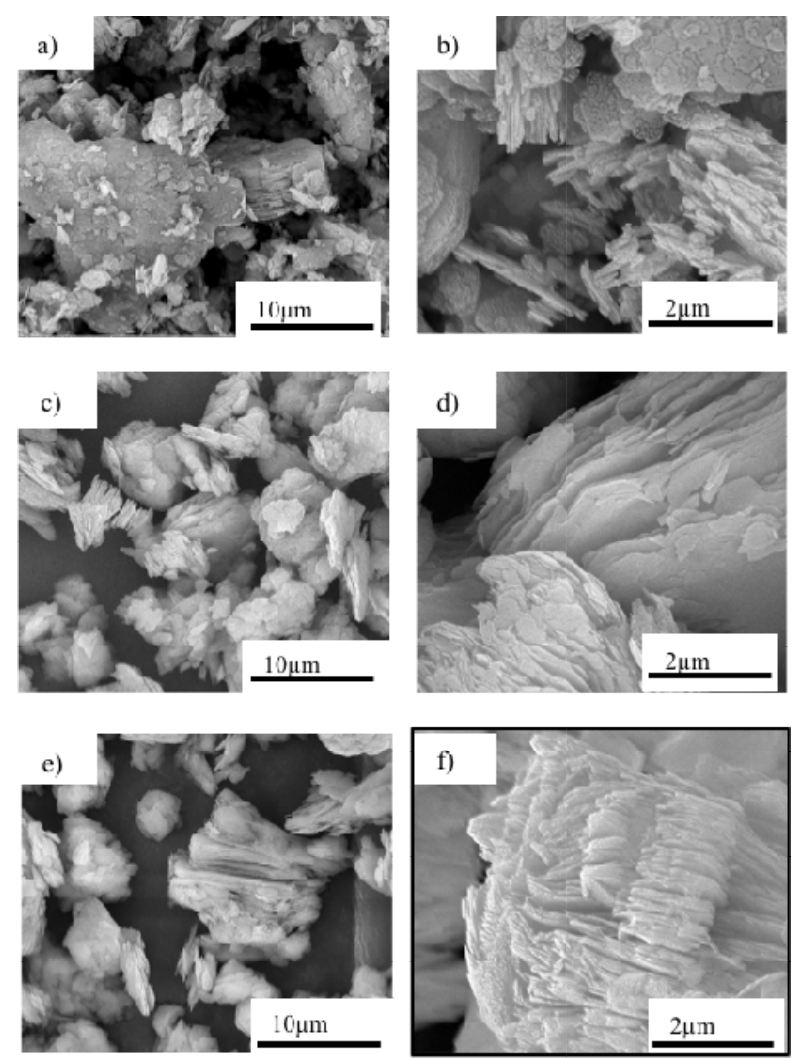

Fig.6. SEM morphology of: a) MetaStar 10000x, b) MetaStar 50000x, c) MK700 10000x, d) MK700 50000x, e) MK700-MT 10000x, f) MK700-MT 50000x magnification

The commercial metakaolin MetaStar were also characterized using SEM to observe its particle morphology as presented in fig.6a and 6b. Compared to another results, the particle tends to be denser in the same observed area. The particles still have the same laminate-layered plate as the main structure, but somewhat have different shape to other samples especially to MK700 (fig. 6c and 6d) and MK700-MT (fig. 6e and 6f). This can be occured because of the different raw materials of kaolin used to produce each MetaStar and produced metakaolin. The different source of kaolin will lead to different particle morphology, as can be seen from previous research $[2,15]$.

\section{Conclusions}

In this study, the calcination which was subjected to kaolin was done. The calcination process at a various temperature produce metakaolin which could be compared to commercial metakaolin MetaStar in terms of diffraction pattern (XRD results). All of metakaolin produced have the similar pattern with main peak located at the same diffraction angle $\left(\mathrm{SiO}_{2}\right.$ at 2 望 $=26.60^{\circ}$ to $\left.26.65^{\circ}\right)$. The mechanical treatment given in the process seems to be not affected the diffraction pattern. From the SEM results, the layered-laminate plate-like structure of kaolin can be seen. The structure did not change after milled and calcined, which indicates that milling treatment cannot break down the laminate structure even further and calcination cannot change the visible structure to another form. In the SEM observation of
MetaStar it can be seen that it has the similar laminate structure compared to kaolin and metakaolin produced with a distinct particle shape. The different particle shape can indicate the kaolin used to produced MetaStar is different to the kaolin used in this study.

This research was suppored by Universitas Indonesia through Hibah Publikasi Internasional Terindeks untuk Tugas Akhir Mahasiswa (Hibah PITTA) program. (2535/UN2.R3.1/HKP.05.00/2018).

\section{References}

[1] G. Varga. (2007). The structure of kaolinite and metakaolinite. Épitöanyag 59. évf. 2007. 1. Szám (http://dx.doi.org/10.14382/epitoanyag-jsbcm.2007.2)

[2] A. Souri, F. Golestani-Fard, R. Naghizadeh, S. Veiseh. An investigation on pozzolanic activity of Iranian kaolins obtained by thermal treatment. J. App. Clay Sci103, 34-39. (2015)

[3] H. Cheng, Q. Lui, J. Yang, S. Ma, R. L. Frost. The thermal behavior of kaolinite intercalation complexes-A review. Thermochimica Acta545, 1-13. (2012)

[4] P. Ptáček, F. Frajkorová, F. Šoukal, T. Opravil. Kinetics and mechanism of three stages of thermal transformation of kaolinite to metakaolinite. Powder Technology264, 439-445. (2014)

[5] B. R. Ilic, A. A. Mitrovic, L. R. Mlicic. Thermal treatment of kaolin clay to obtain metakaolin. Hom. Ind.64, 351-356. (2010)

[6] Z. Zuhun, Y. Xiao, Z. Huajun, H. Sudong, C. Yue. Activating Process of Geopolymer Source Material: Kaolinite. J. of Wuhan University of Technology-Mater. Sci. Ed. (2009)

[7] A. M. Rashad. Metakaolin as cementitious material: History, scours, production and composition - A comprehensive overview. Construction and Building Materials41, 303-318. (2013)

[8] A. Souri, H. Kazemi-Kamyab, R. Snellings, R. Naghizadeh, F. Golestani-Fard, K Scivener. Pozzolanic activity of mechanochemically and thermally activated kaolins in cement. Cement and Concrete Research77, 47-59. (2015)

[9] A. Mitrovic, M. Zdujic. Preparation of pozzolanic addition by mechanical treatment of kaolin clay. Int. J. of Mineral Processing132, 59-66. (2014)

[10] ASTM C618-17. Standard Specification for Coal Fly Ash and Raw or Calcined Natural Pozzolan for Use in Concrete. ASTM International. West Conshohocken, PA. 2017. www.astm.org

[11] M. B. Ramli, A. O. Richard. Characterization of metakaolin and study on early age mechanical strength of hybrid cementitious properties. J. of Construction and Building Materials121, 599-611. (2016)

[12] M. Fitos, E. Badogiannis, S. Tsivilis, M. Perakki. Pozzolanic activity of thermally and mechanically treated kaolins of hydrothermal origin. J. App. Clay Sci.116-117, 182192. (2015) 
[13] A. K. Chakraborty. 2014. Phase transformation of kaolinite clay. New York: Springer India. ISBN 978-81-3221154-9

[14] A. M. Menshaz, M. Azmi, Z. Arifin. Characterization of metakaolin treated at different calcination temperatures. AIP Conference Proceedings 1892, 20-28. (2017)
[15] S. Zhang, Q. Liu, Y. Yang, D. Wang, J. He, L. Sun. Preparation, morphology, and structure of kaolinites with various aspect ratios. J. App. Clay Sci. 117-122. (2017) 